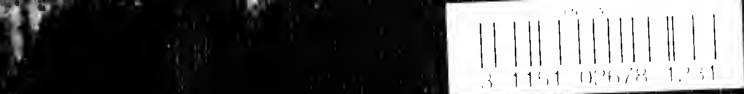

t.

$$
\frac{1}{4}
$$




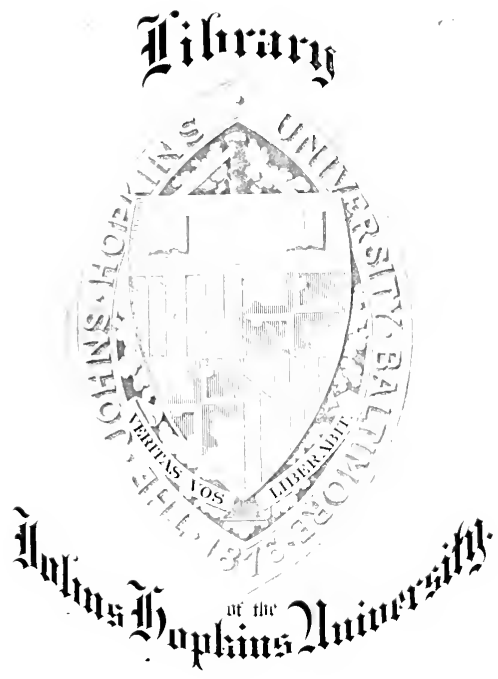




\section{.}

$$
\text { • }
$$





\title{
DETECTING EFFICIENCY
}

OF THE RESISTANCE-CAFACITY COUPLDD ANILIFIER TO 6000 IETSRS.

DISSER'PATION

SUBUITTED TO THE BOARD OF UNIVERSITY STUDIES OF THE JOHIS HOPKINS UNIVHRSITY IN CONFORUITY “ITH THE RE UIREUENTS FOR THE DEGREE OF DOCTCR OF PHILOSOPHY

W. G. Brambacher.

\author{
BAIT LiORE
}

1922. 
. 
Table of Contents.

1. Introductory

2. Apparatus

3. Variation of Coupling Capacity

4. Variation of iave Length

5. Amplification. 



\section{Introductory.}

The detecting efficiency of the resistance-capacity courled electron tube amplifier has been discussed by E. O. Hulburt.* He derived a formula which indicated the connection betreen it and the constants of the electron tubes and the coupline circuits. His experiments showed that the theoretical relation held in the region from 400 to 1600 neters.

The detecting efficiercy was defined by the relation $\lim _{A \rightarrow 0} \frac{b_{0}}{A^{2}}$ in which $A$ and $b_{0}$ are the amplitudes, respectively, of the input grid potential and of the rectified component of the output plate current.

Consider the high frequency amplifier of two tubes as shown in Figure 1. For this type of amplifier Hulburt derived the following formula, subject to the conditions that there be no recification in the first tube and no grid filament current in the second tube

$$
\frac{b_{0}}{A^{2}}=n k^{2} g_{1}^{2}\left[\frac{\left(g_{2} g_{3}-x_{4} x_{5}\right)^{2}+\left[x_{4}\left(z_{3}+g_{2}+g_{3}\right)+g_{3}\right)^{2}+\left[g_{4}\right]^{2}\left(g_{1}+g_{2}+g_{3}\right)+x_{5}\left(g_{1}+g_{2}\right)}{\left(g_{2}+g_{3}+\frac{x_{6}}{x_{4}} g_{2}\right)^{2}+\left(x_{5}-\frac{g_{2} g_{3}}{x_{4}}\right)^{2}}\right]
$$

in which $A$ is the armlitude of the radio frequency potential impressed on the grid of the first tube, $b_{0}$ is the reotified component of the resulting radio frequency current in the plate 



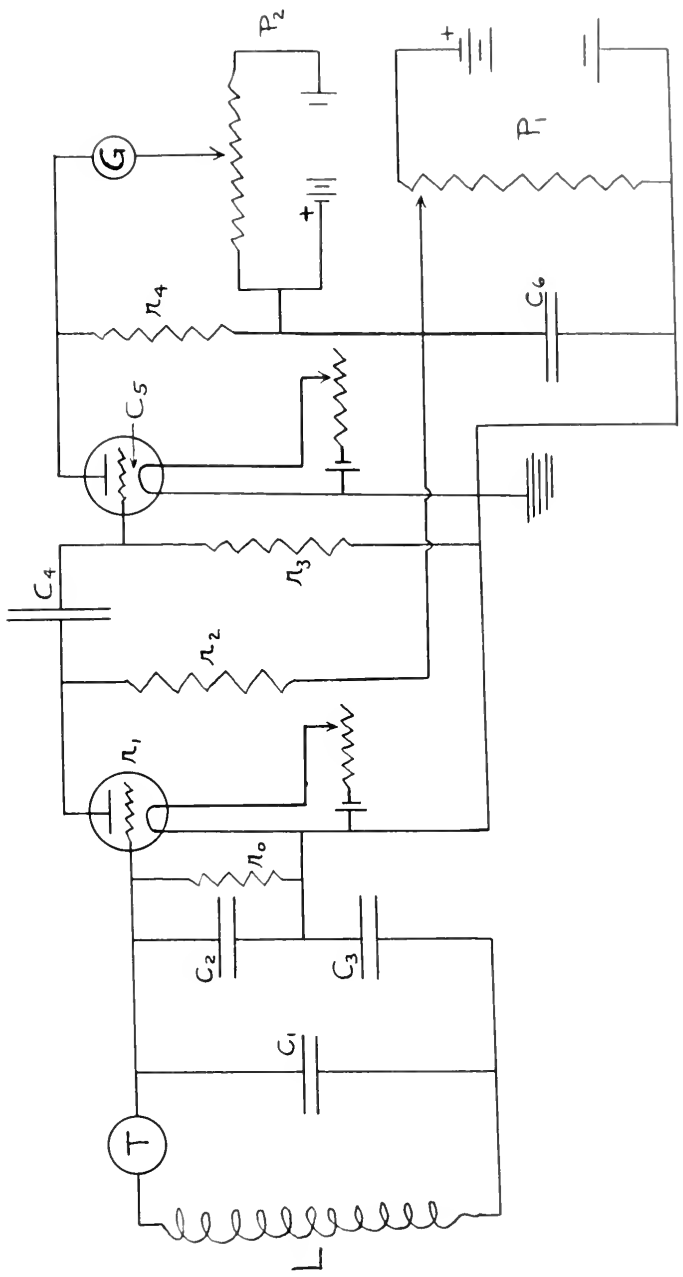



circuit of the second tube; $k 18$ the amplification oonstant of the first tube. $r$, is the internal resistance of the first tube from filament to plate. $C_{5}$ is the filament-grid capacity of the second tube. Fesistances $\mathbf{r}_{2}$ and $\mathbf{r}_{3}$ and capaoity $C_{4}$ are as shown in Figure 1.

Let $\frac{\omega}{2 I}$ be the frequency of the impressed voltage.

Let

$$
\begin{array}{ll}
\frac{1}{r_{1}}=g_{1} & \omega \mathrm{C}_{4}=\mathrm{X}_{4} \\
\frac{1}{r_{2}}=g_{2} & \omega \mathrm{C}_{5}=\mathrm{X}_{5} \\
\frac{1}{r_{3}}=g_{3} &
\end{array}
$$

One term has not been ciefined, which is

$$
n=\frac{b_{0}}{E g^{2}}
$$

where $\mathrm{E}_{\mathrm{g}}$ is the amplitude of potential impressed on the grid of the second tube. n does not depend on the frequency of the impressed voltage. (See Figure 6)

Let

$$
\begin{aligned}
& g_{2} g_{5}-x_{4} x_{5} \equiv a \\
& x_{4}\left(g_{2}+g_{3}\right)+x_{5} g_{2} \equiv b
\end{aligned}
$$

Phen, more acourately, the formula may be written

$$
\underline{b}_{A^{2}}=n K^{2} g^{2} \frac{a\left(a+g_{1} g_{3}\right)+b\left(b+x_{4} g_{1}+x_{5} g_{1}\right)}{\frac{\left(a+g_{1} g_{3}\right)^{2}\left(b+x_{4} g_{4}+x_{5} g_{4}\right)^{2}}{\left(g_{2}+g_{3}+\frac{x_{5}}{x_{4}} g_{2}\right)^{2}+\left(x_{5}-\frac{\left.-g_{2} g_{3}\right)^{2}}{x_{4}}\right.}}
$$


.

$-$ 
It is to be noticed that this formula fives the detectine efficiency in terms of the constants of the electron tubes and the coupling circults. Also Formula (1) is an approzImation of (2), the use of which is justified under obv1ous conditions.

The object of this paper is to make the experimental measurements necessary in or ver to test Formula (1) for long wave-lengths, and to this end measurements were made frop 1000 to 6200 meters.

\section{Apparatus.}

The apparatus consisted of a condenser potantial divider, the amplifier and a D'Arsonval galvanometer. Tho ar rangement is essentially that of figure 1. The potential divider consisted of the coil L, the Weston thermo-galvanometer $\mathrm{T}$, and the condensers $\mathrm{C}_{1}, \mathrm{C}_{2}$ and $\mathrm{C}_{3} \cdot \mathrm{Th}$ is apparatus has been previously described by hulburt and reit.* The potential impressed on the grid of eirst tube may be found from

$$
A=\frac{c_{3} I}{\omega\left(c_{1} C_{2}+c_{1} c_{3}+c_{2} c_{3}\right)}
$$

in which I is the effective current measured by $T$. By coupling I to a suitable electron tube generating set, unmodulated high frequency voltage of a small known amplitude and 

frequency was impresseci on the grid of the first tube. 'the high resistance leak $r_{0}$ was connected across $C_{2}$ to insure a definite value of the grid potential during the exyeriment. The effect of $\mathbf{r}_{0}$ upon the impedance of $\mathrm{C}_{2}$ was negligible because $C_{2}$ was large ( $\theta$ ther $.05, .1$, or .2 $\mathrm{MF}$ ) and the frequencles used were of the order of $10^{5}$.

The amplifier was a two-tube one with resistance capacity ooupling. The tubes were General Electric Company tubes, Radiatron type UV 201; they were used with the 11lament current of .94 amperes and had a common plate voltage supply of 52.3 volts. Separate storage cells supplied each filament. The electron enission was found to be sensitive to external temperature changes. It was therefore found necessary to enclose the electron tubes in covered cardboard tubes in order to keep their temperatures constant. The plate battery was shunted by a $1.75 \mathrm{MF}$ condenser $\mathrm{C}_{6}$. The resistance $r_{2}$ was $115 \times 10^{3}$ ohms and $r_{3}$ was $360 \times 10^{3}$ ohms. The resistances $\mathbf{r}_{0}, \mathbf{r}_{2}$ and $\mathbf{r}_{3}$ were non-inductive being of the type described by Hulburt.* These were fourd to give satisfactory service. The value of the resistance for high erequency currents was assumed the same as that measured with direct current.

* Loo. cit. 
$\rightarrow$ 
The change in the value of $t$ e rectified high frequency component of the plate current of the seoond tube of the amplifier, designated by $b_{0}$, was measured by a D'irsonval galvanometer, G, Figure 1, connected across a resistance $\mathbf{r}_{4}$ placed in the plate circuit. $\mathbf{r}_{4}$ was 60,000 ohms. The galvanometer had a resistance of 9.0 ohms and a sensibility of $5.8 \times 10^{-8}$ amperes per millimeter deflection on a scale 125 cms. distant. $P_{1}$ and $P_{2}$ rig. 1 were potential dividers, $P_{1}$ serving to keop the plate voltage at the desired value, and $P_{2}$ to compensate for the potential drop in the resistance $\mathbf{r}_{4}$ so that the galvanometer rested approximately at zero. hen the grid voltage of the first tube was changed, a deflection of the galvenometer resulted which was proportional to the change in the rectified high frequency component of the output plate current.

It was important that the filament currents renain constant. Any change in these currents resulted in a shift of the operating point of the tubes. The electron tubes were seasoned before every series of readings until a reasonably constant condition of filament current and electron enission was reached. In order to eliminate the error due to the usual slow drift of the galvanometer, the two zero readings were averaged. It was found that the grid leak $\mathbf{r}_{0}$ gave a constant potential of nearly zero on the grid of the first 

tube when its value was $246 \times 10^{3}$ ohms. Lhis value was not oritical. For large vilues of $\mathbf{r}_{0}$, the value of the frid potential shifted with the necestiry varicl of $\mathrm{C}_{3} \cdot$ i kolster decremeter, calibrated by the Pureau of Standerds was used to determine the wave-lengths of the high frequency current.

\section{Variation of Coupling Capacity.}

The reading of the coupling condenser $\mathrm{C}_{4}$ was varied at each reading, a number of input potentials were impressed on the grid of the first tube and the corresponding galvanoneter deflections were noted. From the reading of $T$, the thermo-galvanometer, and a knowledge of the capacities $C_{1}$. $\mathrm{C}_{2}$ and $\mathrm{C}_{3}$, the amplitude of the change of the input grid voltage, A was computed, using formula (3). Three sets of readings were taken, at wave-lengths 1016,3070 and 6235 meters. The resulting curves, with $b_{0}$ the ovdinates and $A^{2}$ the abscissa, are shown in Fig. 2,3 and 4. It can be se日n that for each value of $C_{4}$ for all three wave-lengths the $b_{0}-A^{2}$ curves are straight lines. This fact has been established by a large number of similar curves, not shown here. The curves for any one wave-length are plotted from data taken with the potential divider condensers $\mathrm{C}_{2}$ and $\mathrm{C}_{3}$ held constant. A change in the value of $\mathrm{C}_{3}$ caused the curve for any particular value of $\mathrm{C}_{4}$ 

to shift and also to change its slope. This is shown in F1g. 3 by the ourve marked $C_{3}=211$. This fret can be explained by a shift in the operating point of the efrst tube because of a shift in the nornal value of the grid potential. $\mathbf{r}_{0}$ had the the value $13 \times 10^{5}$ ohms during these readings. Another point of interest in these curves is that the straight ines do not pass through the origin, although within the limit of experimental error they pass through a common yoint on the $\mathrm{A}^{2}$ axis. This seens to indicate a constant error in the deternination of $\mathrm{A}^{2}$ although a check up of the calibrations revealed no differences large enough for compensation. It is also of interest to notice that for each wave-length there is practically the same current range $\left(b_{0}\right)$ but that there is a large range in the value of $\mathrm{A}^{2}$; for 1016 meters, .006 to .016; for 3070 meters, .002 to .005 and for 6235 meters, .005 to .0015 volts.

The main fact, however, remains that the straight lines were obtained, as is predicted by formula (1).

In order to further test formula (1) the slopes of the curves corresponding to each value of $\mathrm{C}_{4}$ were deternined and then plotted against values of $\mathrm{C}_{4}$ for each of the three wave-lengths as shown in Fig. 5. That is, experimental values of $\frac{\mathrm{b}}{\mathrm{A}^{2}}$ are plotted against values of $\mathrm{C}_{4}$. Then, from formula (1) the theoretical value was computed. Values of the constants not before glven, $r$, , 

the direct current filament to plate resistance of the first tube, was $60 \times 10^{3}$ ohns; $\mathrm{C}_{5}$, the filament-grid capacity of the second tube was 18MLF. This was measured in its socket and included the capacity of its lead wires, which were short, however. As neither $n$ or $k$ were determined experimentally, the computei curve was made to coincide with the experimental curve at $\mathrm{C}_{4}$ equal to 628M.MF. The computed curves are the broken lines. While the asreement between the experimental and computed curve is not exact, it is quite satisfactory, revealing no marked differences in behavior for two of the wave-lengths oonsidered, while for wave-length $3070 \mathrm{~m}$. the agre日ment is good. No change in the character of the computed curve was found whether formula (2) or its approximation (1) was used.

\section{Variation of ave-length.}

The coupling capacity $\mathrm{C}_{4}$ was kept at its maximum value of 628 iff, $\mathbf{r}_{2}, \mathbf{r}_{3}$ and $\mathbf{r}_{4}$ remained at their former values of $115 \mathrm{x}$ $10^{3}, 360 \times 10^{3}$ and $60 \times 10^{3}$ ohrs. A series of readings were taken so that the variation of detecting efficiency with wavelength could be deternined. The experimental results are given in the full line curve of Fig. 6.

As the curve connecting the square of the input grid potential and the rectifled component of output plate current does not pass through the origin, a series of readings was taken at each wave-length, a curve drawn and the slope determined. This slope 

is $\frac{b_{0}}{A^{2}}$ - The experimental curves just mentioned were straight lines within experimental error.

In order to keep the grid potential of the first tube constant for the entire range of wave-lengths used, it was found necessary to fix its value near zero, which was done by making $r_{0}$ equal $246 \times 10^{3}$ ohms. This was tested by obtaining the deflection of the galvanometer when the condenser $\mathrm{C}_{2}$ was short oirculted, there being no high frequency current in the input circuit. This test was made when the condensers $\mathrm{C}$, and $\mathrm{C}_{3}$ had values corresponding to the range of wave-lengths used. $\mathrm{C}_{2}$ was .2WF throughout the run.

The computed curve, shown dotted in $\mathrm{H}^{\prime} \mathrm{ig}$. 6 , was made to agree with the experimental curve in the neighborhood of 4100 meters. It was computed from formula (2), as the pproximate formula (1) differed with it over the range of wave-lengths computed.

whe agreement of the two curves is substantial througiout the entire range, and, it is belleved, would be even better, if the apparatus had been used with better control over the grid potentials. Thus, the simple theory underlying Hulburt's formula, is in agreement with experiments thus far made.

The curve of detecting efficiency against wave-length 

given by Hulburt from 600 to 1600 meters is a straight line. This is in agreement with the curve given in Fif. 6 and also with an unpublished curve carried down to 1100 meters.

It is seen that the detecting efficiency at higher wave-lengths ( lower frequencies) becomes independent of the wave-length.

The detecting efficiency was found to be excerdingity sensitive to any chanees in the electron tube constants. It would be interesting to determine the detecting efficiency for a positive grid potential on the first tube, where the amplification is a maximu, to see whether the formula held. It would be less difficult, perhaps, to get observations for this condition.

\section{5. imolification.}

It was necessary to test the independence of $\mathrm{n}$ with respeot to wave-length. By definition

$$
\mathrm{n} \equiv \frac{\mathrm{b}_{\mathrm{O}}}{\mathrm{Eg}^{2}}
$$

where $b_{0}$ is the rectified component of the output plate current and $\mathrm{E}_{\mathrm{g}}$ is the potential variation on the rid of the second tube.

In order to measure $n$ the input voltage was impressei

direct $y$ on the second tube, the first tube being disconnected, and the outrut plate current was found for a series of wave-lengths. 

As before, sufficlent observations were made for each wavelength oo that a curve could be urawn and the slope deternined. the slope was $\frac{\mathrm{b}_{\mathrm{J}}}{\mathrm{E}_{\mathrm{T}}^{2}}$. The curves so determined were straight lines. n was found to be sensibly constant for all wave-lengths as is shown in Curve 3, rig. 6 .

If the ordinate of curve 1 be divided by the ordinate of Curve 3 at the same vave-length, both of Fis. 6, the quotient is the amplification of the current obtained by the use of the amplifying electron tube. That is, th quotient gives the number of times the rectified component of the plate ourrent, $b_{0}$ is increased by the use of two tubes instead of one. The quotients, or current amrifications, are the ordinates on the left marein of Fig. 6. If telephones are used the sound intensity ampliffcation is proportional to the square of these numbers.

This problem was suggested to me by Dr. E. O. Hulburt, now at the State University of Iowa, who derlved the formula underlying the investigation. 



$$
\begin{gathered}
\text { Figure } 2 \\
\text { Wave Length } 1016 \mathrm{~m} .
\end{gathered}
$$

$\times 10^{-8}$ AMperes

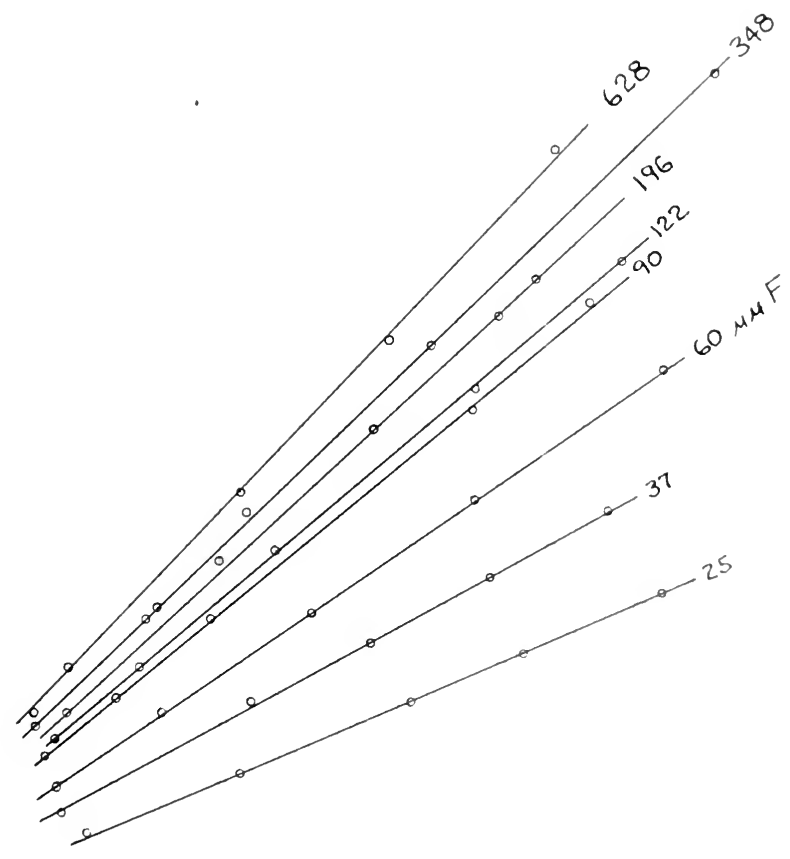


. 


\section{Figure 3 \\ Wave Length $3070 \mathrm{~m}$.}

$\times 10^{-8}$ AMPERES

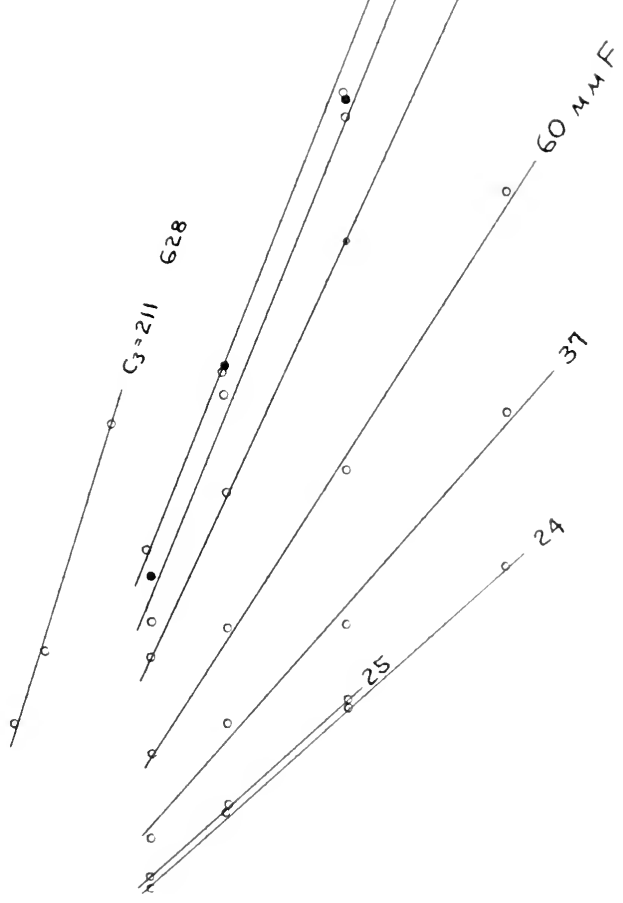

$\begin{array}{llllll}0 & 100 & 200 & 300 & 400 & 500 \cdot 10^{-5}\end{array}$ 

FIGURE 4

Wave Length 6235 m.

$\times 10^{-8}$ AMPERES

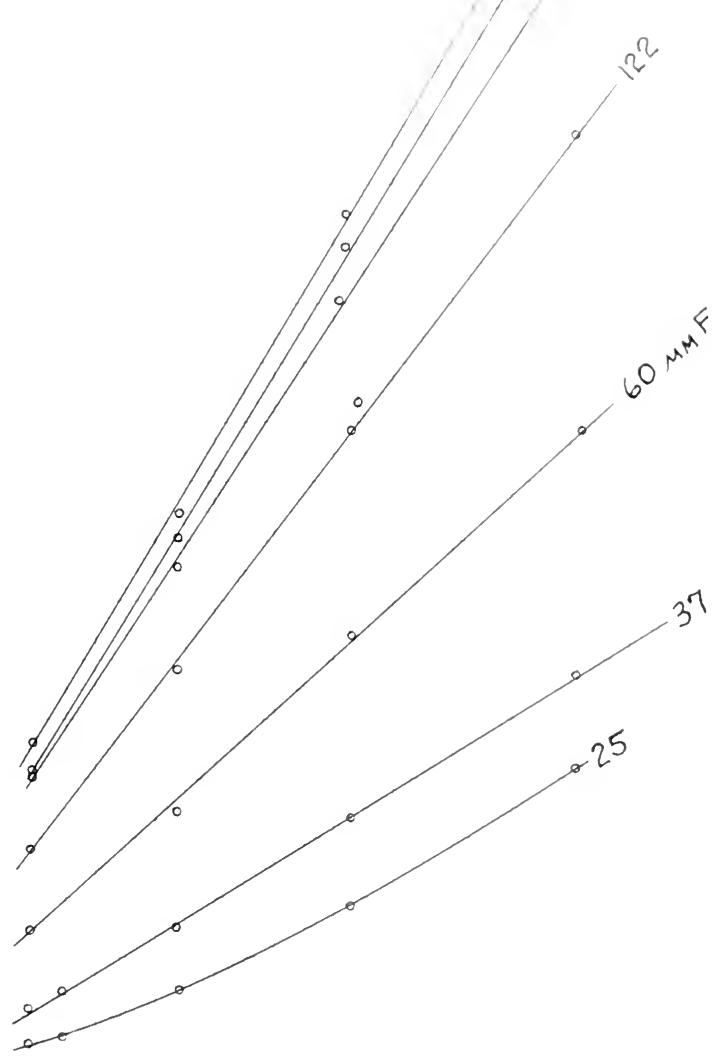



$\times 10^{-5}$

\section{Wave Length $6235 \mathrm{~m}$.}

$\times 10^{-5}$

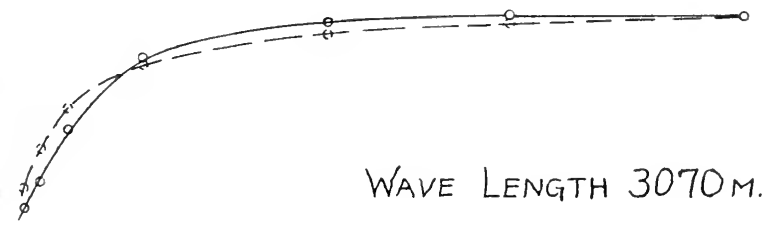

$10^{-6}$

Wave Length $1016 \mathrm{~m}$.

Figure 5

$\$$

WAve LeNGTH $3070 \mathrm{~m}$.

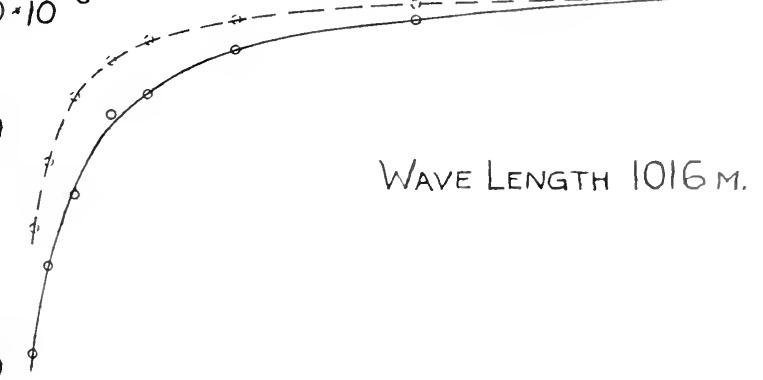

$100 \quad 200 \quad 300 \quad 400 \quad 500 \quad 600 \quad$ и. F 



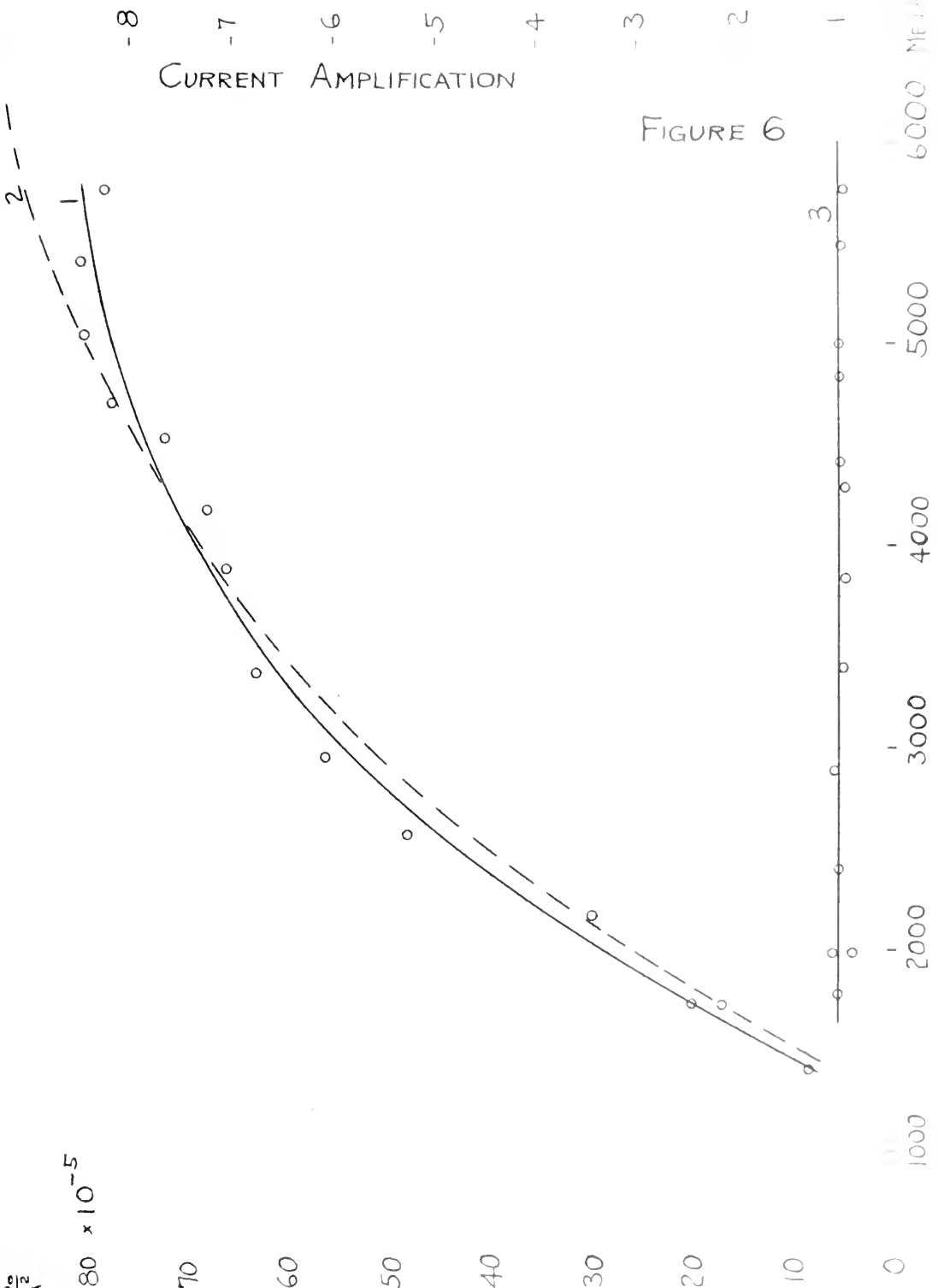



Willam George Erombacher, son of Henry and Flizabeth (Case Brombacher was born in Cleveland, Ohio February 23, 1891. He received his early education in the unicago lligh chools. In 1915 he received the degree of Bachelor of Arts from Lake Forest College with Shield Honor B, and in 1917 the degree of Master of Arts from the sarne college. During the year 1918 he was in the United States Army, stationed at the Bureau of Standards, afterwards filling the position of Assistant Physicist at the Bureau.

In 1919 he entered the Johns Ho pkins University as a graduate student and as an Instructor in Physics. He folloned the courses of Professors Ames, Wood and Associate Professor Pfund in Physics, Associate Professor Wurnaghan in Mathematics and Professor Reid in Ceophysics. 



○. 
